\title{
Who Asks For Voter Identification? Explaining Poll-Worker Discretion
}

\author{
Lonna Rae Atkeson University of New Mexico \\ Yann P. Kerevel Lewis University \\ R. Michael Alvarez California Institute of Technology \\ Thad E. Hall University of Utah
}

\begin{abstract}
As street-level bureaucrats, poll workers bear the primary responsibility for implementing voter identification requirements. Voter identification requirements are not implemented equally across groups of voters, and poll workers exercise substantial discretion in how they apply election law. In states with minimal and varying identification requirements, poll workers appear to treat especially minority voters differently, requesting more stringent voter identification. We explain why poll workers are different from other street-level bureaucrats and how traditional mechanisms of control have little impact on limiting poll-worker discretion. We test why many poll workers appear not to follow the law using a post-election survey of New Mexico poll workers. We find little evidence that race, training, or partisanship matters. Instead, poll worker attitudes toward photo-identification policies and their educational attainment influences implementation of voter-identification laws.
\end{abstract}

A s street-level bureaucrats, poll workers bear the primary responsibility for implementing voter-identification requirements mandated by the Help America Vote Act (HAVA) or by state and local governments. ${ }^{1}$ Currently, about 29 states require some identification process, with 12 states requiring photo identification. Studies of poll-worker discretion find voter ID laws are often not administered equally across racial and gender groups, but existing literature has not clearly explained why voter ID laws are inconsistently applied (Ansolabehere 2009; Atkeson et al. 2010; Cobb et al. 2012), which is the concern of this study.

The street-level bureaucracy literature has not generally considered the particular problems facing election administrators (cf. Alvarez and Hall 2006). Previous research on street-level bureaucrats focuses on permanent employees (e.g., Lipsky 1980; MaynardMoody and Musheno 2003), while the street-level bureaucrats of elections are temporary employees who create a particular set of problems for the local election official (LEO). Furthermore, mechanisms of control to reduce discretion and ensure street-level bureaucrats do not "shirk" or "sabotage" particular policies have limited applicability for poll workers because of the short term of their employment and limited opportunity for the development of shared norms or organization structure (Brehm and Gates 1997; Meyers and Vorsanger 2003). Finally, the street-level bureaucracy literature largely shares the norm that discretion is a valuable tool for street-level bureaucrats to ensure responsiveness and effectiveness. However, when dealing with voting rights, it is not clear that poll-worker discretion can have positive consequences. We contribute to the literature on street-level bureaucracy by addressing how variation in the terms of employment alters the ability to control discretion.

We address these important issues using data from a survey of randomly selected New Mexico poll workers, across four counties, in the November 2008 election. We supplement the poll-worker survey with observational data from the same election and same counties across over 200 New Mexico precincts and a 2008 post-election voter survey. We find evidence

\footnotetext{
${ }^{1}$ An online appendix with supplementary material for this article is posted at http://dx.doi.org/10.1017/S0022381614000528. Data and supporting materials necessary to reproduce the numerical results will be made available at dataverse (www.thedata.org) upon publication.
} 
that the state's voter identification law is routinely not followed. We then consider whether poll-worker training, demographic characteristics, and attitudes of the poll workers can explain the variation in application of the voter identification law and find poll-worker attitudes about voter identification and poll-worker education levels largely explain variation in implementation and consider the implications of our study on public policy.

\section{Previous Research on Voter Identification}

The debate over the implementation of state voter identification laws first focused on its relationship to turnout. At present, this research is inconclusive: some have found that voter identification laws have no effect on turnout at either the aggregate or individual level (Lott 2006; Mycoff, Wagner, and Wilson 2007), while others have found that strict voter identification laws decrease turnout among certain segments of the population (Alvarez, Bailey, and Katz 2011; Alvarez, Katz, and Bailey 2007; Hood and Bullock 2012; Vercellotti and Anderson 2006). Among the latter set of studies, there is debate on whether these laws disproportionately effect minorities and which forms of voter identification requirements significantly reduce turnout (Alvarez, Katz, and Bailey 2007; Hood and Bullock 2012; Vercellotti and Anderson 2006).

More recently, scholars have examined the procedural consequences of voter identification laws and whether identification laws are administered equally across different social groups. This is an important question because, historically, laws like these have been used to create barriers to participation and have been implemented unequally across segments of the voting population (Keyssar 2000). In the case of voter identification, the effects on minorities might be subtle because these laws may not directly result in observable changes in turnout but may affect increases in provisional voting or voter confidence. Recent voter studies in New Mexico in 2006 and 2008 found significant variation in the application of identification requirements; Hispanic, male, and Election Day voters were more likely to be asked for photo identification when none was required (Alvarez, Atkeson, and Hall 2013; Atkeson, Alvarez, and Hall 2010; Atkeson et al. 2010). Other state and national studies showed minorities, both blacks and Hispanics, were more likely than whites to report showing identification (Ansolabehere 2009; Cobb et al. 2012). In addition, an observational study in Los Angeles found that $29 \%$ of poll workers incorrectly indicated to observers that it was the law in California to show photo identification, and a significantly greater percentage of poll workers who worked in precincts with higher concentrations of minorities made such claims (Barreto, Cohen-Marks, and Woods 2009). Studies also found that states with minimal voter identification laws were more likely to have variation in the implementation of voter identification across racial groups with blacks and Hispanics more likely to indicate they showed identification more frequently than whites (Alvarez et al. 2010; Atkeson et al. 2010).

\section{Poll Workers as Street-Level Bureaucrats}

The concept of street-level bureaucrat refers to public servants with a high degree of discretion in their duties, who enjoy a certain degree of autonomy from administrative officials, and are directly involved in delivering services to citizens (Lipsky 1980, 13-16). Even though they are temporary employees, poll workers meet the criteria of street-level bureaucrats possessing power, authority, discretion, and autonomy. For example, Alvarez and Hall (2006) argue poll workers have tremendous autonomy and the GAO noted that poll workers have "the final authority on interpreting guidance in areas such as deciding who can vote and determining voter intent" $(2001,160)$. Because there are often hundreds or even thousands of voting locations in an urban county, oversight by election officials is very difficult, and problem solving is often delayed by hours as local election officials respond to voter or observer complaints. This authority, and absence of oversight, as a streetlevel bureaucrat allows poll workers the discretion to resolve problems as they see fit and make final decisions at the polls leading to various principalagent problems (Alvarez and Hall 2006; MacDonald and Cain 2005).

The street-level bureaucracy literature does not adequately speak to the use of temporary workers as is common in election administration. Election administrators often rely on temporary workers to run the polls, to recount ballots, and to perform election audits. Scholars of street-level bureaucracy focus primarily on teachers, social-service workers, and police officers who work within permanent 
organizations, generally depend upon their positions for their primary source of income, and must rely on discretion to effectively deliver the services they are required to provide (Maynard-Moody and Musheno 2003; Vinzant and Crothers 1998). By contrast, poll workers are temporary workers who, at most, work only a few days a year, and many work only a few elections before they retire. ${ }^{2}$ Because they are temporary workers, poll workers are not likely to be part of the organizational culture of election administrators and, unlike teachers and police officers, are less likely to have shared norms or conformity (Meyers and Vorsanger 2003; Wilkins and Williams 2008). This temporary status heightens agency problems and enhances the discretion of poll workers.

\section{Influence of Beliefs and Identities on Decision Making}

Research on street-level bureaucrats helps to explain the decision-making and task environment faced by poll workers (e.g., Hall, Monson, and Patterson 2009). When rules and procedures are straightforward, easy to follow and applicable to the situation at hand, it is more likely that street-level bureaucrats will follow the rules and limit their discretion. In contrast, complex rules and procedures often increase discretion (Maynard-Moody and Musheno 2003, 93; Meyers and Vorsanger 2003). For poll workers, the level of complexity of voter-identification requirements is likely to influence the extent of poll-worker discretion. Evidence suggests that discretion is enhanced, and implementation problematic, when laws are complicated and provide multiple ways in which a voter can be identified or provide different identification requirements for different types of voters.

New Mexico, the case studied here, has a complicated voter identification law that allows voters to choose the way in which they are identified, but legally each voter must present a verbal or written form of identification. About 16 states have similar laws or only HAVA-compliant voter ID requirements. In New Mexico, the minimum identification required under state law in 2008 was for each voter to state her name, registration address, and birth year. Voters could also choose to show a physical form of identification, such as a voter registration card, driver's license, or utility bill. If the voter opted for a

\footnotetext{
${ }^{2}$ Six percent of poll workers indicated this was their first election; another 36\% worked two; $31 \%$ worked between three and five; $17 \%$ worked between six and 10; and $10 \%$ worked more than 10 lections.
}

photographic identification, it did not have to contain the voter's address; if the voter opted for a nonphoto form of identification, the document had to include an address, but it did not have to match the voter registration rolls. ${ }^{3}$ In addition, the election context for voter identification laws is complicated. The city of Albuquerque, which is located in Bernalillo County and is the largest city in New Mexico, offered a voter referendum that easily passed in 2005, which required all voters to show photo identification in city elections, but was not implemented until the fall of 2009. Differences across jurisdictional contexts likely increase discrepancies and confusion related to the law and its implementation.

In addition, the extent of discretion available to poll workers may vary by voting mode. Early voting and vote centers reduce the number of polling places and hence poll workers, making it easier for election administrators to supervise poll-worker behavior and select higher-quality poll workers. Moreover, in the case of early voting and its extended time frame, election administrators have the ability to exert greater control over poll workers and administer sanctions to address any complaints brought by staff, observers, or voters. In New Mexico, early voters were given a small form that asked for name, registration address, and birth year, all of the requirements necessary for voter identification under the law. Nevertheless, some early voters indicated they were still asked for photo identification. However, given the differences in oversight and repeated exposure to election rules that early voting provides, we hypothesize:

H1: Poll workers will be less likely to incorrectly ask voters for identification during early voting compared to Election Day voting.

In contrast, there are numerous ways in which poll workers exercise their discretion on Election Day. ${ }^{4}$ They decide the precinct set-up, providing voters with more or less privacy. They encourage or discourage the use of machines designed to aid minority voters needing language assistance and voters with disabilities that prevent them from voting a normal ballot. They determine the process for checking in, getting a ballot, and placing it into the machine. They also often determine at the end of the day voter intent for ballots with write-in votes. However, the most

\footnotetext{
${ }^{3} \S 1-1-24$ NMSA 1978.

${ }^{4}$ There are some limits to discretion including other poll workers, poll watchers, and observers. Nevertheless, presiding judges have the final say in the polling place.
} 
important decision poll workers make in their direct interactions with voters is deciding whether or not a person is an eligible voter-whether they have the appropriate identification or not, and consequently whether they will get a regular ballot, a provisional ballot, or no ballot at all.

Maynard-Moody and Musheno (2003, 3-7) argue street-level workers not only rely on rules and procedures to make decisions but also on their own value systems and their judgments of the citizen with whom they are interacting. According to this perspective, street-level workers project an identity upon a citizen-client, leading the worker to determine the worthiness of the client and thus which rules and procedures are applied to provide service to him based upon the worker's value system (93-94, 154-55). In the extreme, this sort of decision making can lead workers to bend over backwards to serve their clients or engage in discriminatory actions. ${ }^{5}$

The key to applying this insight to poll workers is to specify which identities and beliefs are critical for understanding the implementation of voter identification requirements. We suggest the race of poll workers and of voters is likely to be of critical importance based on the history of voting rights in the United States. Debates surrounding voter identification are also closely tied to the two major political parties, suggesting that the partisanship of poll workers will influence their implementation of voter identification requirements. Finally, specific attitudes about voter identification held by poll workers are likely to influence implementation.

Barriers to electoral participation have been justified as protecting the system against fraud (Burnham 1965; Ginsburg 1986; Kleppner 1982; McGerr 1986). Historically, these barriers were also intended as a means of disenfranchising specific groups of voters, such as certain immigrant groups, African Americans, or the poor (Allen and Allen 1981; Burnham 1986; Keyssar 2000; Reynolds 1993), although contemporary supporters of such laws dispute these intentions. Therefore, the goal of election reformers was not simply to prevent fraud but also to disenfranchise voters. In the most notorious example of procedural voter disenfranchisement, blacks and immigrants were subject to literacy tests prior to registration, disenfranchising many otherwise eligible voters. After the passage of the Voting Rights Act, voter rolls saw huge increases in

\footnotetext{
${ }^{5} \mathrm{We}$ observed a poll judge allowing a voter to vote an Election Day ballot even though she had been provided an absentee ballot and had been sent in, which was against the law.
}

black and white registration (Alt 1994; Stanley 1987). Today, variation in voter identification implementation may be seen as a method of intentional or even unintentional intimidation used against certain types of voters, especially minorities.

Hispanics in particular may be perceived as a more likely group of voters who might be engaging in fraud, given the larger immigration debate and their perceived potential status as noncitizens. The results of several studies have found that Hispanic and African American voters were asked to show physical forms of identification more than nonHispanic whites (Alvarez et al. 2010; Ansolabehere 2009; Atkeson et al. 2010; Atkeson, Alvarez, and Hall 2010; Cobb et al. 2012). As the race or ethnicity of voters has been shown to be key in the application of voter identification requirements, it is also possible the race of poll workers influences how they implement the law. Minority poll workers may be more aware of this history and for the potential discriminatory consequences of incorrectly applying voter identification requirements.

H2: Minority poll workers will be less likely to ask for photo identification compared to white poll workers.

Other factors may also be important to determining if poll workers ask voters for photo identification. The national debate surrounding voter identification issues is highly partisan (Ansolabehere and Persily 2008), with Democrats focused on voter access and the possibility of disenfranchising eligible voters who may not have adequate identification and Republicans focused on protecting the system against fraud (Alvarez et al., N.d.; Ansolabehere and Persily 2008; Liebschutz and Palazzolo 2005).

H3: Republican poll workers will be more likely to ask for photo identification compared to Democratic or Independent poll workers.

We also consider the important role that attitudes may play in the implementation of voter identification laws. Given the amount of discretion that poll workers have in this realm, they may be motivated by perceptions of the election process and the role that voter identification plays in this process. For streetlevel bureaucrats, the personal nature of the workerclient interaction matters to the prescription of policy (Maynard-Moody and Musheno 2003). However, poll workers have minimal personal interaction with most voters they encounter. A primary factor for their implementation motivation may be normative-the observed difference between what they believe voter identification policies should be and the laws that are 
actually on the books. Because personal attitudes towards multiple aspects of the election process may shape discretionary behavior, it is likely that attitudes about access to voting and photo identification influence their implementation of voter identification policies.

H4: Poll workers who are more concerned about the integrity of elections will be more likely to ask for photo identification than poll workers who are more concerned about access to voting.

H5: Poll workers who support photo identification policies will be more likely to ask for photo identification.

\section{Controlling Discretion}

Given the discretion of street-level bureaucrats, there has been much discussion of how to control it (e.g., Meyers and Vorsanger 2003). Most scholars of street-level bureaucracy recognize that supervisory control is often weak and the promulgation of more regulation has little or contradictory effects on the extent of discretion. Since street-level bureaucrats often make decisions based on their preferences, the primary way to regulate discretion is by shaping these preferences. Shaping the preferences of street-level bureaucrats can be achieved through the development of shared professional norms, adequate training, and the recruitment of capable individuals (Brehm and Gates 1997, 202; Vinzant and Crothers 1998, 155-56).

Yet, poll workers differ from other street-level workers in key ways. Because poll workers typically undergo a quick training process and only work, at most, a few days a year, they are less likely to have a complete grasp of the rules and procedures compared to other street-level bureaucrats. This lack of knowledge means poll workers may have less incentive or ability to follow the prescribed rules and procedures precisely because it is either too costly to fully understand them or they may simply not be aware that their own behavior is in direct contradiction to the law.

Even though many poll workers work more than one election, ${ }^{6}$ the infrequent nature of elections means it is unlikely that experienced poll workers fully retain their knowledge of election law and procedure from election to election. It is also the case that election laws and procedures change

${ }^{6}$ See footnote 4. dramatically between election cycles. In addition, poll workers are temporary as opposed to career street-level bureaucrats, and the inconsistent application of rules will have no impact on their future employment or career goals. Importantly, any wrongdoing in the polling place likely has few or no consequences. Except in extreme cases, poll workers do not appear to be fined, reprimanded, denied payment, or otherwise punished for inappropriate or illegal behavior. Therefore, it seems very likely that poll workers are at increased risk of relying on their normative values rather than their training or the law in determining the procedures they implement. In addition, poll workers are likely to adopt their own procedures to make their job easier during an election, especially if the formal rules are complicated or difficult to implement or change in the rules facilitates the election process (Lipsky 1980, 18; Maynard-Moody and Musheno 2003, 12). ${ }^{7}$

Poll workers are typically required to attend a training session prior to Election Day, during which they are instructed in how to run a polling place, including how to identify voters. Although New Mexico law requires poll workers to attend a training session, if poll workers do not show up on Election Day, emergency replacements may be sent in, or voters in line can be asked to serve as a poll worker. ${ }^{8}$ If training is effective, attending a training session should be related to how well a poll worker is able to implement voter identification requirements. In addition, some poll workers receive more extensive training than others. For example, in New Mexico, presiding judges, the persons in charge of polling places, are required to attend a more extensive training than poll clerks, suggesting presiding judges may be more likely to understand the voter identification requirements and implement them correctly.

H6: Poll workers who attended training will be more likely to apply voter identification requirements correctly than poll workers who did not attend training.

H7: Presiding judges will be more likely to apply voter identification requirements correctly compared to election clerks.

However, our own observations of poll worker training in Bernalillo County, New Mexico, suggest

${ }^{7}$ Our data show that $17 \%$ of poll workers indicated they asked for identification because they had trouble hearing or found it easier to read their name from the ID card.

${ }^{8} \mathrm{We}$ observed several recruitments during our 2008 Election Day observations. 
training may not be effective, and the individual beliefs of poll workers may more accurately explain variation in the implementation of voter identification policies. ${ }^{9}$ The poll-worker training sessions typically lasted one to two hours, depending on whether it was a training session for presiding judges (longer) or for election clerks (shorter). Training took place anywhere from a few days to a few weeks before Election Day, which suggests many poll workers may have forgotten some of the more intricate details of election law. All poll workers were given a manual to study and bring with them to the polling place. There was no incentive to ensure poll workers read or understood the manual, although we did observe many poll workers and presiding judges consulting the manual on Election Day when various issues arose. There were no poll-worker performance tests, online training, or hands-on learning opportunities.

During training, county officials in charge of the training explained to all poll workers the complicated voter identification law, stressing that it is the voter's choice as to how they authenticate themselves to the election workers. However, trainers would preface their explanation of the law by stating their awareness that some poll workers did not agree with the law, but that poll workers were to follow the law on Election Day. In addition, in nearly all of the training sessions, some poll workers voiced their disagreement with the voter identification law directly to the county officials during discussion.

Furthermore, unlike other street-level workers, poll workers rarely enter their job with a group of knowledgeable and experienced coworkers and may not benefit from learning about the rules and procedures from other poll workers. Poll workers are extremely unlikely to develop an organizational culture with shared professional norms to guide their conduct as is common with other street-level bureaucrats. However, some individuals who serve as poll workers through multiple elections may be especially committed to the job and thus have developed a set of norms that would encourage them to correctly apply voter identification requirements. Alternatively, however, experience could make them more confident in making their own decisions and increase pollworker voter identification discretion.

\footnotetext{
${ }^{9}$ Each author of this article as well as most members of our observation team went to at least one training session in Bernalillo, New Mexico. Our discussions with and observations of poll workers in the other counties on Election Day suggest that our experience in Bernalillo County was general.
}

H8: Poll workers who have more experience working previous elections should be more likely to follow election law.

An important way to control discretion among street-level bureaucrats is through the recruitment process. For example, street-level bureaucrats who are more highly educated may more effectively exercise their discretion in a positive way (Vinzant and Crothers 1998, 155). Extending this logic to poll workers, a poll worker's level of education may be related to their ability to correctly implement election law and voter identification requirements. Since voter identification requirements are complicated in New Mexico, we expect poll workers with higher levels of education will be more likely to understand and follow the law relating to voter identification.

H9: More educated poll workers will be less likely to ask for photo identification.

\section{Data and Methodology}

The primary source of data for this study come from a post-election random survey of poll workers in four New Mexico counties (Bernalillo, Santa Fe, San Juan, and Doña Ana) after the November 2008 general election. ${ }^{10}$ In New Mexico, the poll workers in each precinct are part of a precinct board, headed by a presiding judge who has special training in the management of the election. Presiding judges are responsible for the conduct of the election in their precinct and therefore are the poll workers most likely to engage the voter and the precinct system at all possible points. Therefore, we included each presiding judge in the four counties we examined in our sample to have adequate data on all aspects of the election process in the precinct. ${ }^{11} \mathrm{We}$ also randomly selected two additional members of the precinct board-poll clerks-from every precinct in each county to include in the sample. In Bernalillo County, we also selected an additional two sample members from each precinct. ${ }^{12}$

\footnotetext{
${ }^{10}$ See the online supplemental Appendix S1 for a detailed description of our research design.

${ }^{11}$ Technically, there are three poll-worker positions: the presiding judge, the election judge, and the clerk. However, only the presiding-judge position differs from the others in training and duties.

${ }^{12}$ We did this because Bernalillo County had about two additional poll workers per precinct.
} 
After the election, the local county clerk sent each sampled poll worker an invitation letter informing them of the upcoming survey encouraging their participation. The surveys were mailed on January 12,2009 , and we continued accepting returned and completed surveys until April 30, 2009. We sent a reminder postcard on January 29, 2009 to those individuals who had not responded. All individuals who had not returned a survey by February 18, 2009 were mailed a new survey, and a second follow-up reminder postcard was mailed on March 1. The overall response rate was $69.1 \%$ using Response Rate 2 of the American Association of Public Opinion Research (AAPOR 2011).

In addition to the poll-worker survey data, we use two other data sources to test our hypotheses. First, we use a probability-based post-election mixed mode (Internet or mail) survey of New Mexico voters to ascertain whether voters were identified in accordance with the law (Atkeson, Adams, and Alvarez, n.d.). We use these data to determine whether the poll-worker responses toward identification of voters reflect the voter experience during the same election. Second, we use Election Day precinct observation reports in the same four New Mexico counties studied in the poll-worker survey during the same election (See Atkeson, Alvarez, and Hall 2010 and Appendix S1). Each county had at least two teams of two individuals trained in polling-place operations fill out observations reports across a wide variety of precincts. Using this data provides a further measurement check on the poll-worker and voter-survey data (Alvarez, Atkeson, and Hall 2013).

\section{Dependent Variable}

To test voter identification implementation behavior, we asked, "When a voter approached without any form of identification, how often did you ask voters to show a form of photo identification?" Response choices included: "very often" (16.4\%), "somewhat often" (19.4\%), "not too often" (35.2\%), and "not at all" $(29.0 \%) .{ }^{13}$ Asking for photo identification is the most restrictive form of identification a poll worker can ask from a voter and is also contrary to New Mexico election law. This ordinal dependent variable is coded on a 4-point scale from "not at all" (coded 1) to "very often" (coded " 4 "). The mean response to this question was 2.23. Although a majority of poll workers do not ask for photo identification

\footnotetext{
${ }^{13}$ Frequency percentages are weighted by age, county, and precinct position.
}

"somewhat" or "very often," 36\% of poll workers indicate they asked voters for photo identification consistently. This initial descriptive result suggests that poll workers engage in discretion and that poll workers vary in the type of identification they require from voters.

\section{Independent Variables}

We use four groups of independent variables: partisanship, political attitudes, variables that capture the training, position, and experience of the poll worker, and demographic characteristics. We include pollworker partisanship, coded as a series of dummy variables, with dichotomous measures for Republican and independent poll workers and Democrats as the excluded category.

We measure poll-worker attitudes toward voter identification with two variables. ${ }^{14}$ The first is a question that asked poll workers to choose which statement is more important, "Ensuring that everyone who is eligible has the right to vote" or "Protecting the voting system against fraud." Nearly two-thirds $(63 \%)$ of poll workers indicated it was more important to ensure the right to vote than to protect the system against fraud (27\%). Ensuring everyone has the right to vote is coded " 1 ," and thus we expect a negative relationship because those who think ensuring the right to vote is more important will be less likely to ask for photo identification. We also control for those respondents who answered "don't know" (10\%) to this question to prevent modeling problems that would otherwise occur because of listwise deletion.

For the second attitudinal variable, we asked each poll worker to "indicate whether you strongly agree, somewhat agree, neither agree nor disagree, somewhat disagree, or strongly disagree with the following statement: Photo identification should be required of each voter at the polls to prevent fraud." The variable is coded on a 5-point Likert scale with "strongly agree" coded as " 5 " and "strongly disagree" coded as "1." We find that poll workers overwhelmingly support photo identification policies; $52.9 \%$ of poll workers strongly agreed with this statement, along with another $19.7 \%$ who somewhat agreed, $10.8 \%$ who neither agreed nor disagreed, $7.1 \%$ who somewhat disagreed, and $9.5 \%$ who strongly disagreed.

\footnotetext{
${ }^{14}$ In previous versions of this article, we included various measures that captured poll-worker attitudes towards the prevalence of fraud. Inclusion of these variables did not produce statistically or substantively interesting results or effect on the results presented here.
} 
We measure training with a dummy variable for those who attended one or more training sessions (coded " 0 ") and those that did not attend a training session (coded " 1 "). ${ }^{15}$ We also capture those poll workers who worked early voting with a dummy variable.

We measure experience by the number of previous elections worked coded on a continuous scale from " 1 " to " 10 or more." A separate dummy variable is also included for those individuals who worked their first election in 2008. We also include a variable that measures the poll worker's position, with presiding judges coded " 1 ," and all other poll workers coded " 0. ."

Our final set of independent variables is demographic characteristics. We include poll-worker selfidentified ethnicity coded as a series of dummy variables. These include Hispanic, black, Native Americans, and other minorities (this includes Asians and "other"). A majority of our respondents were white (53\%), but $30 \%$ identified as Hispanic; about $4 \%$ were Native American, and about $2 \%$ were black. Education is coded on an 8-point scale from some high school to advanced graduate work. A dummy variable is included for female poll workers, and age is coded in years. We have no a priori expectations for either gender or age in our models.

Election administration is managed at the county level and, therefore, we use county fixed effects: three county dummies (San Juan, Doña Ana, and Santa Fe counties) in our model, with Bernalillo County (the largest in New Mexico) being the comparison county. ${ }^{16}$

\section{Results}

\section{Variation in Implementation of the Voter Identification Law}

We first present information drawn from observational data to provide confirming evidence of the variable application of voter identification laws at the polls in the 2008 election and to provide contextual information on our case. The Election Day observations confirm the discretion available to poll workers

\footnotetext{
${ }^{15}$ Only 48 poll workers in our sample indicated they did not attend training.

${ }^{16}$ When we were not able to identify the poll worker's county, we included them with the mode, Bernalillo County. The results are the same if these cases are deleted through listwise deletion.
}

in identifying voters. We even saw a variety of voter identification rules being used within precincts across different voters. Members of the observation team witnessed the following procedures: (1) voters volunteered identification (picture or other type of identification card, especially voter registration cards) without being asked by the poll workers; (2) voters were told to look up their name in the voter identification roll and provide their corresponding number to the poll workers without showing any additional identification; (3) voters were asked for their name only or their name with either address or birth year, but not all three; (4) voters were asked correctly for their name, address, and year of birth; (5) voters were immediately asked for identification, sometimes picture identification, upon arrival; (6) voters were recognized upon entering the polling site and asked to sign the voter rolls; (7) voters who could not be found in the precinct roll were then asked for identification so that the poll workers could call the county clerk and request registration status and the correct voter precinct; (8) poll workers simply held out their hand presumably with the expectation that an individual's identification would be placed in it.

Data from our convenience observations indicated that about one-quarter of precincts we visited were asking for a physical form of voter identification. In addition, only three in five (61\%) precincts were asking for identification properly (Atkeson, Alvarez, and Hall 2010).

Because many voters may have not been asked for identification but instead just offered the poll-worker identification, it is important to probe this issue further from the voter's perspective. In the voter survey, respondents were asked the following twopart question: "When you went to vote were you ASKED to show PHOTO-identification, like a driver's license, did you just provide a PHOTO-ID to the poll worker without them asking or were you identified in some other way?" Respondents who said "some other way" in response to that first question were asked a follow-up question with a list of choices: "If you were not asked to show photo-identification or did not just automatically provide identification to the poll worker, how were you identified at the polls? Did you: show your voter registration card, state your name, state your name and address, state your name and birth year, state your name, address and birth year, I wrote my name, address and birth year on a piece of paper, or I did it another way."

These responses were collapsed so that voters were classified as being identified correctly or incorrectly. The results demonstrate that the law was often not 
TABle 1 Ordered Logit Regression: Why Poll Workers Ask for Photo Identification

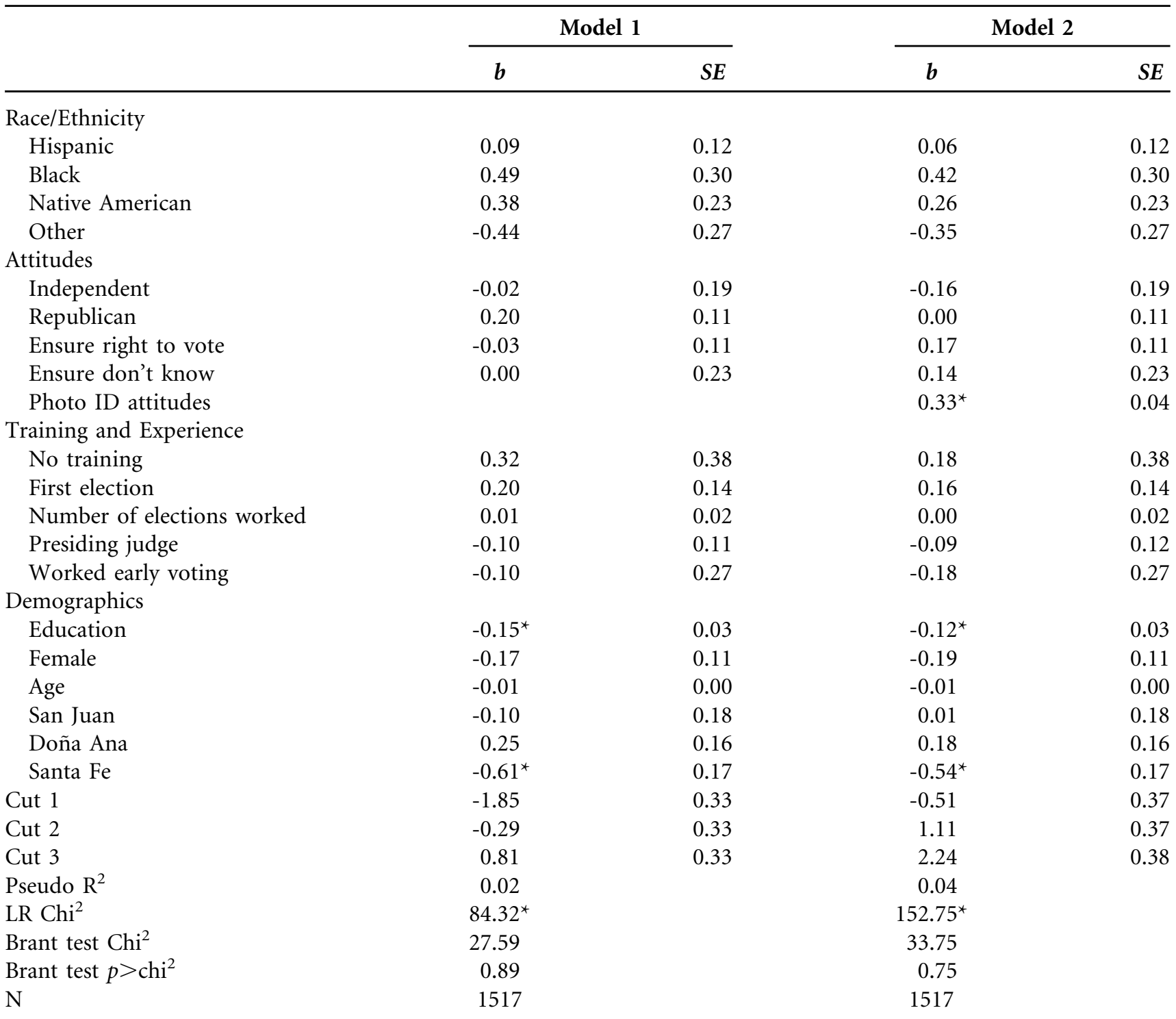

Note: Dependent variable: 4-point scale from the question, "How often did you ask voters to show a form of photo identification?" Models do not violate the parallel regression assumption according to the Brant test. ${ }^{\star} p<.05$ two-tailed test.

applied correctly. Just under half of all voters (49\%) were identified correctly, and just over half $51 \%$ were not identified correctly.

These results varied by whether a voter voted at an early voting site or on Election Day. A minority of Election Day voters (40\%) were identified correctly but a majority of early voters (54\%) were identified correctly ( $p<.05$, two tailed test). We also examine how this identification law was applied across Hispanic and non-Hispanic voters. Data on early voting indicated that self-identified Hispanics and non-Hispanics were identified correctly or incorrectly equally. However, this was not the case in precincts on Election Day. A little over half (52\%) of self-identified non-Hispanics were identified correctly but only $41 \%$ of self-identified Hispanics were identified correctly ( $\mathrm{p}<.05$, two tailed test). These results provide support for our first hypothesis that poll workers are less likely to incorrectly identify voters during early voting compared to Election Day.

\section{Implementation of Voter Identification by Poll Workers}

To determine how attitudes, identities, training, and experience influence poll-worker behavior, we turn to our poll-worker survey. Models 1 and 2 in Table 1 examine poll-worker behavior, with the dependent variable being how often the poll worker asked voters to show a form of photo identification. Model 1 
Figure 1 Influence of Attitudes about Photo Identification on Asking for Photo Identification

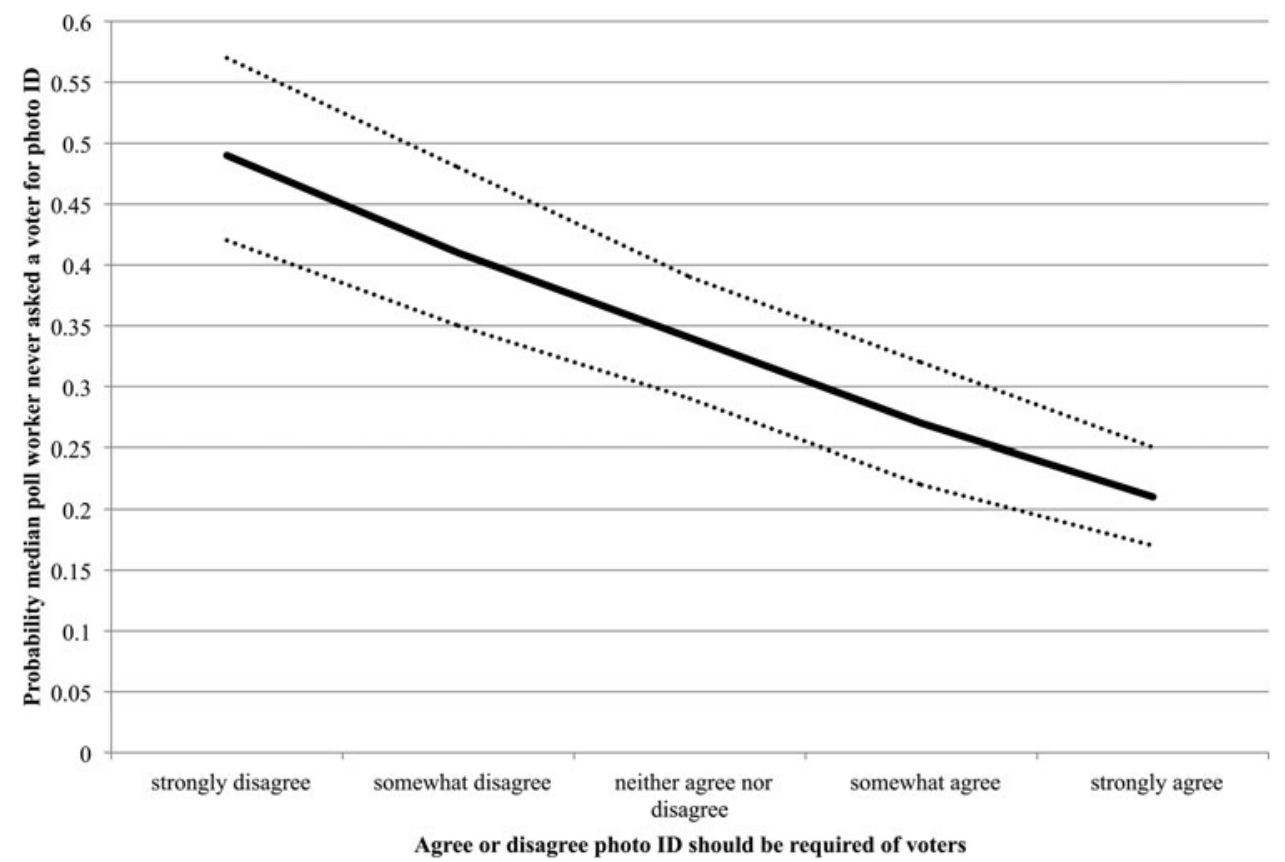

presents the potential determinants of whether or not poll workers asked for photo identification, and Model 2 presents the same analysis except we also include the poll-worker attitudes toward photo identification. We use an ordered logit regression in our analysis, with the variable coded from 1 ("not at all") to 4 ("very often"). To simplify the discussion of the effect of these variables, we use Clarify (King, Tomz, and Wittenberg 2000) to generate the predicted probability of how each factor changes the probability of support for the dependent variable for a hypothetical poll worker.

Overall, we do not find much support for many of the hypotheses. In Model 1, we find some weak but contradictory evidence that black poll workers were more likely to ask for photo identification compared to white poll workers ( $p<.10$, two-tailed test), but this effect disappears in Model 2 once we account for attitudes about photo identification. We also find some confirming evidence that Republican poll workers were more likely to ask for photo identification compared to Democratic poll workers $(p<.10$, two-tailed test), but again, this effect disappears once we account for attitudes about photo identification. In both models, we find no support that poll-worker attitudes about election integrity and access to voting influence their behavior. Finally, we find little support to suggest that training, experience working elections, serving as a presiding judge, or working early voting have a strong influence on asking for photo identification, although the direction of the effects are in the expected direction.

However, we do find significant support for two of our hypotheses, namely attitudes about photo identification and the poll worker's level of education. Figure 1 plots the predicted probability the median poll worker will not ask for photo identification (i.e., responded "not at all" to the survey) with 95\% confidence intervals based on their attitudes towards photo identification. For the median poll worker who strongly disagrees with requiring photo identification of voters, there is a 0.51 probability they will not ask for photo identification and only a 0.06 probability they will ask for photo identification very often. As the poll worker increasingly supports photo identification, the probability they will not ask for photo identification decreases. The median poll worker who strongly agrees with photo identification has a 0.22 probability of not asking for photo identification and a 0.18 probability of asking for photo identification very often. Substantively, these results suggest that individual attitudes have a strong influence on poll-worker discretion and support our theory that poll workers, when provided with discretion, will likely fall back on their normative judgment of the policy they are required to implement, rather than strictly follow set procedures.

Yet, we see that education moderates the effect of attitudes toward voter identification. Figure 2 plots the predicted probability the median poll worker 
Figure 2 Influence of Education on Asking for Photo Identification

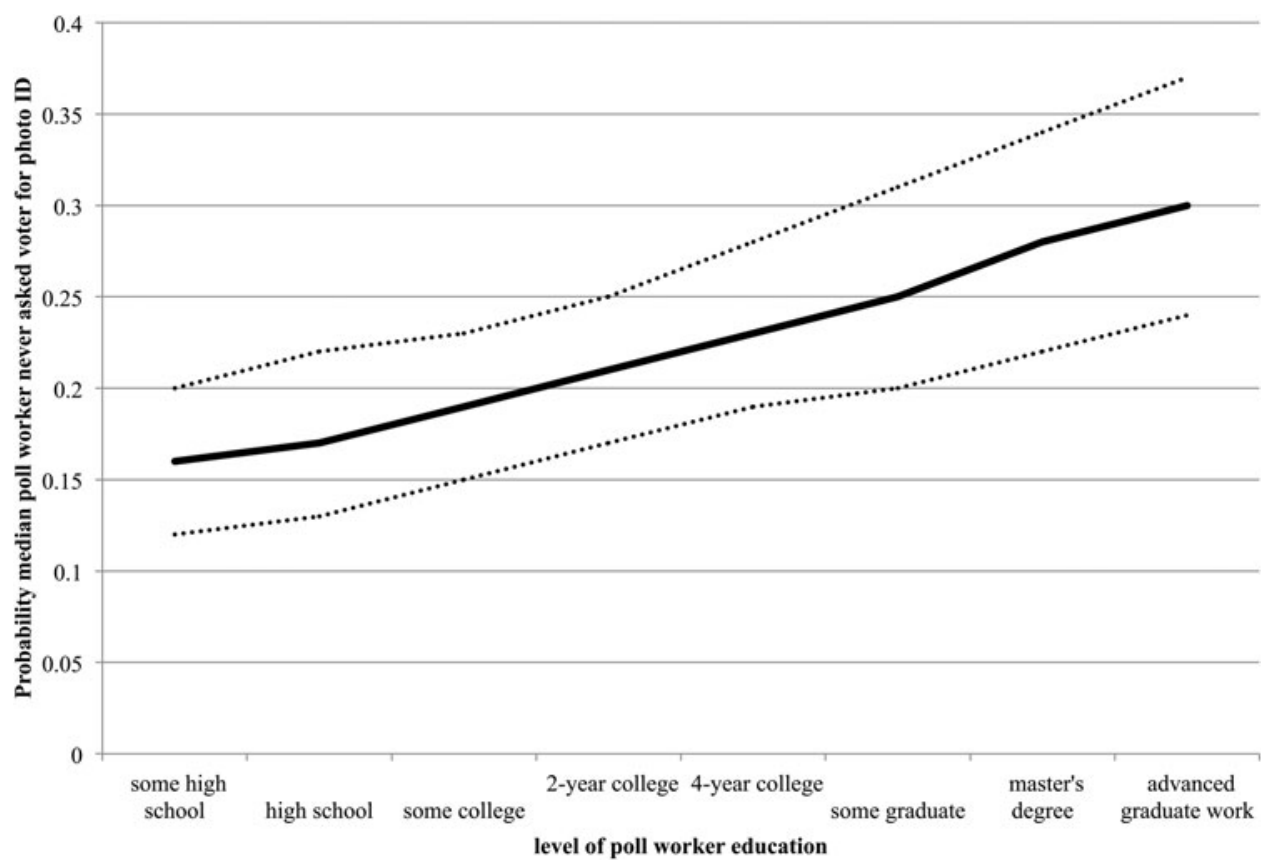

never asked voters for photo identification with 95\% confidence intervals, based on the results in Model 2. Voters with higher levels of education are less likely to ask for photo identification. The median poll worker with a two-year college degree has a 0.22 probability of not asking for photo identification, compared to a 0.17 probability for poll workers with some high school and a 0.32 probability for poll workers with advanced graduate work. The results suggest for a poll worker with high education and strong attitudes toward photo identification, the poll worker's positive desire to ask for identification would be balanced by her education and concomitant recognition that applying her attitudes is not appropriate. Having a better-educated class of workers would seem to be important in ensuring that the poll workers do not rely on their normative judgments. Equally important, this education cannot be provided by the local election officials through training. There is something about educational attainment for which training alone is not a substitute.

Finally, we see that poll workers in Santa Fe County were less likely to ask for photo identification than other county poll workers in both Models 1 and $2 .{ }^{17}$ This last finding is consistent with our Election Day poll observations where we saw that

\footnotetext{
${ }^{17}$ Santa Fe poll workers were significantly less likely to ask for photo identification compared to poll workers in each of the other three counties, and poll workers in Doña Ana and San Juan did not behave significantly different from each other.
}

poll workers in Santa Fe were more likely to implement voter identification policies correctly, although it is not clear what explains this finding.

\section{Conclusions}

Who asks for photo identification from voters? The answer seems to be poll workers who believe it should be required. In general, it seems when poll workers are given substantial discretion in the application of voter identification requirements, they tend to rely on their own attitudes and beliefs rather than the law and their training. In the case of federal elections in New Mexico, where the voter identification requirements are complicated and poll workers must accept many forms of identification, it appears that some poll workers ignore the law and instead rely on their feelings and attitudes about the way voter identification should be administered. A voter identification law that substantially reduces the amount of discretion available to poll workers is likely to reduce the influence of individual attitudes. For example, during early voting in Bernalillo County, when voters approached the polling place they were asked to fill out a card with their name, address, and birth year. Poll workers used this card to look up the voter to ensure they received the proper ballot. This process is much less open to discretionary identification of voters. Similarly formulated processes may reduce 
poll-worker discretion in this process. In addition, we observed the 2009 Albuquerque city elections where photo identification was required of voters for the first time. In our observations, we found poll workers consistently asked for photo identification as required by law and saw little of the variation that was observed in the 2008 elections (Atkeson et al. 2010b). ${ }^{18}$ Our work highlights the importance of implementing clear voter identification procedures that are easy to follow from the poll worker's point of view and are also clearly communicated to voters when they enter the polling place.

However, implementing photo identification laws at the state level does not address the underlying problem we are concerned with here. The motivation for this study was to understand why poll workers were inconsistently applying voter identification requirements, which disproportionately impacted minority groups. Fundamentally, we are concerned with how identification requirements influence every individual's equal access to the voting booth. Poll workers who are allowed to engage in discretion may deny equal access to the voting booth in New Mexico and across the country. Studies like ours are needed in other states to ascertain how procedures that can deny an otherwise eligible voter their right to exercise their franchise are being implemented in polling places, including not only voter identification requirements but other procedures like provisional balloting. Studies also need to determine if such discretion has negative implications for voter turnout.

There are also a number of important implications from these findings beyond policy prescriptions for voter identification requirements. First, previous studies of voter confidence in the accuracy of election outcomes suggest that the voter/poll-worker interaction is a significant factor in explaining levels of voter confidence (Atkeson and Saunders 2007; Hall, Monson, and Patterson 2009). One reason for this finding may be the discretion available to poll workers in providing access to the ballot (see also Claassen et al. 2008). Furthermore, there is some research that finds that voter confidence can influence turnout (Alvarez, Hall, and Llewellyn 2008; Kerevel 2009), suggesting that pollworker discretion can have substantial consequences for voters. Second, previous research has suggested certain groups of voters may be disproportionately impacted

\footnotetext{
${ }^{18}$ However, in the 2013 Albuquerque City elections we saw poll workers requiring additional information of voters that were not required by the law, especially the voter's birthdate, which is only available to the poll worker from the driver's license of the voter.
}

by poll-worker discretion in the application of voter identification laws (Ansolabehere 2009; Atkeson et al. 2010; Cobb et al. 2012; Page and Pitts 2009). If poll workers can use their discretion to discriminate against particular voters, as feared by Page and Pitts (2009), policy makers may wish to consider election reforms that restrict the ability of poll workers to use their own discretion in deciding what type of identification to accept from voters. Clear guidelines and procedures that prevent poll workers from using their discretion are likely the best way for this to be achieved. ${ }^{19}$

Finally, our research has implications for theories of street-level bureaucracy. Specifically, we show that while training, experience, and culture may matter for restraining typical street-level bureaucrats like teachers and police officers, these factors appear unimportant for temporary street-level bureaucrats such as poll workers. For temporary workers who lack the infrastructure and organizational norms that come from permanent employment, our research suggests that attitudes are of primary importance, and therefore election administrators need to be responsive to this problem by creating procedures that encourage responsiveness to the law.

\section{Acknowledgments}

Support for this research was provided by the Pew Center on the States and the JEHT Foundation. We thank the following election officials for their assistance: Bernalillo County Clerk Maggie Toulouse Oliver and her Deputy Robert Adams, Doña Ana County Clerk Lynn Ellins, San Juan County Clerks Fran Hanhardt and Debbie Holmes, Santa Fe County Clerk Valerie Espinoza and her Deputy Denise Lamb, New Mexico Secretary of State Mary Herrera, and research assistants Lisa A. Bryant and David Odegard.

\section{References}

Allen, Howard W., and Kay Warren Allen. 1981. "Vote Fraud and Data Validity." In Analyzing Electoral History: A Guide to the Study of American Voting Behavior, eds. Jerome M. Clubb et al. Beverly Hills, CA: Sage, 153-92.

Alt, James E. 1994. "The Impact of the Voting Rights Act on Black and White Voter Registration in the South." In Quiet Revolution in the South: The Impact of the Voting Rights Act,

\footnotetext{
${ }^{19}$ In 2012 , the county revamped their training and made formal procedures for identifying voters. This resulted in the lowest rate of poll workers incorrectly identifying voters based upon our observations and clearly reduced discretion suggesting that clear procedures can have an impact on implementation.
} 
1965-1990, eds. Chandler Davidson and Bernard Grofman. Princeton, NJ: Princeton University Press, 351-77.

Alvarez, R. Michael, Lonna Rae Atkeson, and Thad E. Hall. 2013. Evaluating Elections: A Handbook of Methods and Standards. New York: Cambridge University Press.

Alvarez, R. Michael, Steve Ansolabehere, Adam Berinsky, Gabriel Lenz, Charles Stewart, III, and Thad E. Hall. 2010. "Survey of the Performance of the 2008 Elections Final Report." http:// vote.caltech.edu/content/2008-survey-performance-americanelections-0 (accessed April 30, 2014).

Alvarez, R. Michael, and Thad E. Hall. 2006. "Controlling Democracy: The Principal-Agent Problem in Election Administration.” Policy Studies Journal 5 (1): 40-56.

Alvarez, R. Michael, Jonathan Katz, and Delia Bailey. 2007. "The Effect of Voter Identifications on Turnout." Working Paper \#57, Caltech/MIT Voting Technology Project.

Alvarez, R. Michael, Delia Bailey, and Jonathan N. Katz. 2011. "An Empirical Bayes Approach to Estimating Ordinal Treatment Effects." Political Analysis 19 (1): 20-31.

Alvarez, R. Michael, Thad E. Hall, and Morgan H. Llewellyn. 2008. "Are Americans Confident Their Ballots are Counted?" Journal of Politics 70 (3): 754-66.

Alvarez, R. Michael, Lonna Rae Atkeson, Andrew Sinclair, Thad E. Hall. N.d. "Keeping Voting Safe: Voter Attitudes Toward Voter Access Versus Voter Integrity." Social Science Quarterly. Forthcoming.

American Association for Public Opinion Research (AAPOR). 2011. Standard Definitions: Final Dispositions of Case Codes and Outcome Rates for Surveys. $7^{\text {th }}$ ed. Deerfield, IL.

Ansolabehere, Stephen. 2009. "Effects of Identification Requirements on Voting: Evidence from the Experiences of Voters on Election Day." PS: Political Science \& Politics 42 (1): 127-30.

Ansolabehere, Stephen, and Nathaniel Persily. 2008. "Vote Fraud in the Eye of the Beholder: The Role of Public Opinion in the Challenge to Voter Identification Requirements." Harvard Law Review 121: 1737-74.

Atkeson, Lonna Rae, and Kyle L. Saunders. 2007. "The Effect of Election Administration on Voter Confidence: A Local Matter?" PS: Political Science and Politics 40 (4): 655-60.

Atkeson, Lonna Rae, Lisa A. Bryant, Thad E. Hall, Kyle L. Saunders, and R. Michael Alvarez. 2010. "A New Barrier to Participation: Heterogeneous Application of Voter Identification Policies." Electoral Studies 29 (1): 66-73.

Atkeson, Lonna Rae, R. Michael Alvarez, and Thad E. Hall. 2010b. "Assessing Electoral Performance in New Mexico using an Eco-system Approach: New Mexico 2008." http://www. unm.edu/ atkeson/newmexico.html (accessed June 4, 2014).

Atkeson, Lonna Rae, Alex Adams, and R. Michael Alvarez. N.d. "Nonresponse and Mode Effects in Self and Interviewer Administered Surveys," Political Analysis. Forthcoming.

Atkeson, Lonna Rae, Alex Adams, Lisa Bryant, Angelina Gonzalez-Aller, Willard Hunter, Yann Kerevel, Kimberly Proctor, Lisa Sanchez, and Lori Tafoya. 2010. "The City of Albuquerque 2009 Mayoral Election Administration Report." http://polisci.unm.edu/c-sved/papers-and-projects.html (accessed June 4, 2014).

Barreto, Matt A., Mara Cohen-Marks, and Nathan D. Woods. 2009. "Are All Precincts Created Equal? The Prevalence of Low-Quality Precincts in Low-Income and Minority Communities." Political Research Quarterly 62 (3): 445-58.

Brehm, John, and Scott Gates. 1997. Working, Shirking and Sabotage: Bureaucratic Response to a Democratic Public. Ann Arbor: University of Michigan Press.
Burnham, Walter Dean. 1965. "The Changing Shape of the American Political Universe." American Political Science Review 59 (1): 7-28.

Burnham, Walter Dean. 1986. "Those Nineteenth Century American Voting Turnouts: Fact or Fiction?" Journal of Interdisciplinary History 16: 613-44.

Claassen, Ryan L., David B. Magelby, J. Quin Monson, and Kelly D. Patterson. 2008. "At Your Service": Voter Evaluations of Poll Worker Performance.” American Politics Research 36 (4): 612-34.

Cobb, Rachael V., D. James Greiner, Kevin M. Quinn, Jerry Nickelsburg, Jeffrey F. Timmons, Matthew Groh, Casey Rothschild, and Michael L. Ross. 2012. "Can Voter ID Laws Be Administered in a Race-Neutral Manner? Evidence from the City of Boston in 2008." Quarterly Journal of Political Science 7 (1): 1-33.

General Accounting Office. 2001. "Elections Perspectives on Activities and Challenges across the Nation." GAO-02-3. Washington, DC.

Ginsburg, Gerald. 1986. "Computing Antebellum Turnout: Methods and Models." Journal of Interdisciplinary History 16: 579-611.

Hall, Thad E., J. Quin Monson, and Kelly D. Patterson. 2009. "The Human Dimension of Elections: How Poll Workers Shape Public Confidence in Elections." Political Research Quarterly 62 (3): 507-22.

Hood, M. V., and Charles S. Bullock. 2012. "Much Ado about Nothing? An Empirical Assessment of the Georgia Voter Identification Statute." State Politics \& Policy Quarterly 12 (4): 394-414.

Kerevel, Yann. 2009. Election Management Bodies and Public Confidence in Elections: Lessons from Latin America. Washington, DC: International Foundation for Electoral Systems.

Keyssar, Alexander. 2000. The Right to Vote: The Contested History of Democracy in the United States. New York: Basic Books.

King, Gary, Michael Tomz, and Jason Wittenberg. 2000. "Making the Most of Statistical Analysis: Improving Interpretation and Presentation." American Journal of Political Science 44 (2): 341-55.

Kleppner, Paul. 1982. Who Voted? The Dynamics of Electoral Turnout 1870-1928. New York: Praeger.

Liebschutz, Sarah, and Daniel J. Palazzolo. 2005. "HAVA and the State." Publius Fall: 497-514.

Lipsky, Michael. 1980. Street-Level Bureaucracy: Dilemmas of the Individual in Public Services. New York: Russell Sage.

Lott, John R. 2006. "Evidence of Voter Fraud and the Impact that Regulations to Reduce Fraud Have on Voter Participation Rates." SUNY Binghamton. Unpublished manuscript.

MacDonald, Karin, and Bruce Cain. 2005. "California: Low-Tech Solutions Meet High-Tech Standards." In Election Reform: Politics and Policy, eds. Daniel J Palazzolo and James W. Ceaser. Lexington, MA: Lexington, 123-40.

Maynard-Moody, Steven, and Michael Musheno. 2003. Cops, Teachers, Counselors: Stories from the Front Lines of Public Service. Ann Arbor: University of Michigan Press.

McGerr, Michael E. 1986. The Decline of Popular Politics: The American North, 1865-1928. New York: Oxford University Press.

Meyers, Marcia L., and Susan Vorsanger. 2003. "Street-Level Bureaucrats and the Implementation of Public Policy." In Handbook of Public Administration, eds. B. Guy Peters and Jon Pierre. London: Sage, 245-55. 
Mycoff, Jason D., Michael W. Wagner, and David C. Wilson. 2009. "The Empirical Effect of Voter-ID Laws: Present or Absent?” PS: Political Science \& Politics 42 (1): 121-26.

Page, Antony, and Michael J. Pitts. 2009. "Poll Workers, Election Administration, and the Problem of Implicit Bias." Michigan Journal of Race and Law 15 (1): 1-56.

Reynolds, John F. 1993. "A Symbiotic Relationship: Vote Fraud and Electoral Reform in the Gilded Age," Social Science History 17 (2): 227-51.

Stanley, Harold Watkins. 1987. Voter Mobilization and the Politics of Race: the South and Universal Suffrage, 1952-1984. New York: Praeger.

Vercellotti, Timothy, and David Anderson. 2006. "Protecting the Franchise, or Restricting It? The Effects of Voter Identification Requirements on Turnout." Unpublished manuscript, Rutgers University. http://www.eagleton.rutgers. edu/research/documents/VoterID_Turnout.pdf (accessed June 4, 2014).
Vinzant, Janet Coble, and Lane Crothers. 1998. Street-Level Leadership: Discretion and Legitimacy in Front-Line Public Service. Washington, DC: Georgetown University Press.

Wilkins, Vicky M., and Brian N. Williams. 2008. "Black or Blue: Racial Profiling and Representative Bureaucracy." Public Administration Review 68 (4): 654-64.

Lonna Rae Atkeson is a Professor at the University of New Mexico, Albuquerque, NM 87131.

Yann P. Kerevel is an Assistant Professor at Lewis University, Romeoville, IL 60446

R. Michael Alvarez is a Professor at the California Institute of Technology, Pasadena, CA 91125

Thad E. Hall is an Associate Professor at the University of Utah, Salt Lake City, UT 84112 